
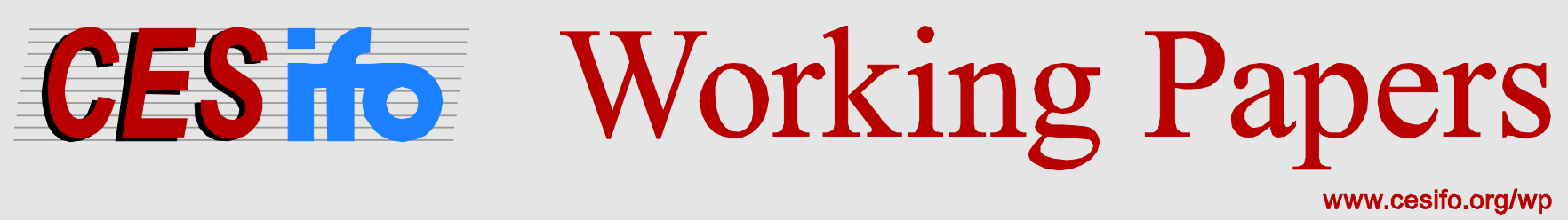

\title{
Explaining the EUA-CER Spread
}

\author{
Marc Gronwald \\ Beat Hintermann
}

\author{
CESIFO WORKING PAPER NO. 5795 \\ CATEGORY 10: ENERGY AND CLIMATE ECONOMICS \\ MARCH 2016
}
An electronic version of the paper may be downloaded
- from the SSRN website:
- from the RePEc website:
- from the CESifo website:
WwW.SSRN.com
www.RePEc.org
www.CESifo-group.org/wp




\title{
Explaining the EUA-CER Spread
}

\begin{abstract}
Because of a link between the EU ETS and the Kyoto Flexible Mechanisms, the emission certificates traded on these markets are in principle interchangeable assets; despite of this, a persistent price difference exists. We explain this price spread using a theoretical model that combines three features: A binding limit for the use of Kyoto offsets within the EU ETS; a disconnect between the price of offsets and their marginal cost of production due to institutional reasons; and uncertainty about future supply and demand of offsets. Our model expresses the offset price as an average of the EUA price and an offset's outside value, weighted by the probability of a binding import limit. Using a detailed dataset on expected offset supply and demand, we provide empirical support for our theory of offset price formation. In addition, we find evidence for informational frictions governing the use of offsets within the EU ETS.
\end{abstract}

JEL-Codes: Q020, Q540, Q580.

Keywords: EU ETS, clean development mechanism, offset demand, EUA-CER spread.

\author{
Marc Gronwald \\ University of Aberdeen \\ Business School \\ Edward Wright Building Block B \\ Dunbar Street \\ United Kingdom - Aberdeen, AB24 3QY \\ mgronwald@abdn.ac.uk
}

\author{
Beat Hintermann \\ University of Basel \\ Department of Economics \\ Peter Merian-Weg 6 \\ Switzerland - 4002 Basel \\ b.hintermann@unibas.ch
}

February 19, 2016 


\section{Introduction}

In order to reduce the European Union's cost to comply with the Kyoto Protocol, firms included in the European Union Emissions Trading Scheme (EU ETS) were allowed to cover a part of their $\mathrm{CO}_{2}$ emissions using offsets from the Kyoto flexible mechanisms. This established a link between the EU ETS and the Kyoto markets in the sense that the two types of emission certificates were interchangeable assets, because both provide the holder with the right to emit one ton of $\mathrm{CO}_{2}$. However, the price for EU allowances (EUAs) has consistently been higher than the price for Certified Emission Reductions (CERs) or Emission Reduction Units (ERUs) 11 Figure 1 shows the corresponding price histories.

Figure 1: Prices for EUAs, CERs (left axis) and their difference (right axis)

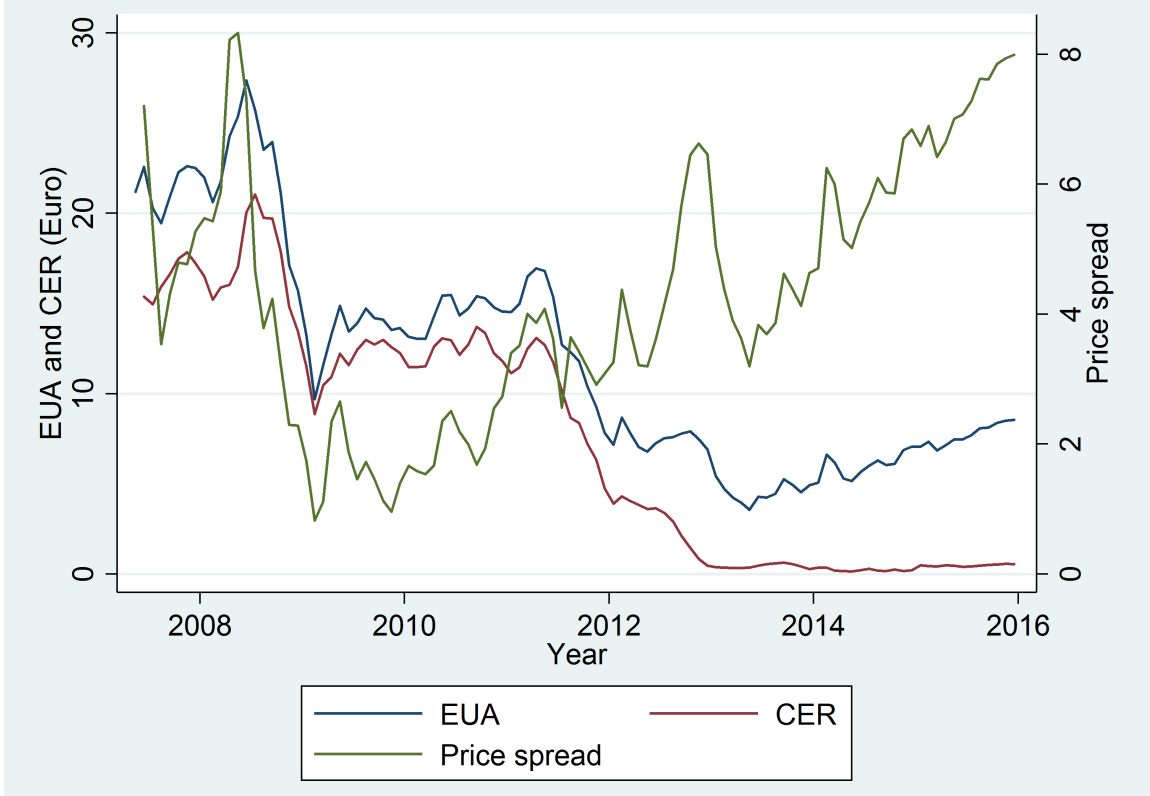

Source: Thomson Reuters Datastream.

Trotignon (2012) and Braun et al. (2015) propose a difference in transactions cost between the two types of carbon certificats as an explanation of the price spread. As an alternative explanation, Nazifi (2013) hypothesizes that the two markets react differently to the same set of fundamentals, which incluldes prices for gas, coal and gold, as well as other macroeconomic indicators.

However, transactions costs would presumably drive a constant wedge between prices, and it is not obvious how they would explain the observed drop of offset prices to zero. In the same vein,

\footnotetext{
${ }^{1}$ Because prices for CERs and ERUs are practically identical, but the liquidity of the former far exceeded that of the latter before 2012, we use the CER price throughout the paper. However, by offset we really mean both types of certificates, and the series of expected excess offset supply is the sum of CERs and ERUs.
} 
it is not easy to imagine that a price driver exists which drives one of the prices to zero but not the other. Our approach extends existing analyses by allowing for a dynamic relationship between the two carbon assets that changes as new information becomes available. In this paper, we propose uncertainty about future offset supply and demand, combined with a limitation of the number of offsets that could be used within the EU ETS, as the main price drivers for Kyoto offsets. Our model explains a significant share of the observed price spread, and it is furthermore consistent with the observation that the price for offsets dropped to nearly zero by the end of 2012.

Without any restrictions, linking two emissions trading schemes leads to a single permit price, equal to the cost of reducing emissions by one ton below the aggregate cap. But since the EU imposed a limit of 1.45 Kyoto offsets that could maximally be used in the EU ETS during Phase II, the prices for EUAs and offsets need not converge. In general, a binding transfer limit breaks the link between two emission permit markets. Once the allowable number of permits has been transferred from the cheaper to the more expensive system, the situation is identical to one where two unlinked permit markets coexist, but where some of the cap has been transferred from one market to the other (for a more detailed illustration of this point, see Grüll and Taschini, 2012).

This reasoning abstracts from uncertainty. However, during much of Phase II and possibly also the beginning of Phase III, it was not clear whether the import limit would turn out to be binding, because the exact number of Kyoto offsets that would eventually become available was not known. Generating emission offsets either via the Clean Development Mechanism (CDM) or by Joint Implementation (JI) is a complicated and lengthy procedure (Trotignon and Leguet, 2009). Between the original proposal and the delivery of verified offsets, a project has to clear a number of administrative stages, at each of which it may be rejected, delayed or its expected number of offsets adjusted. From market participants' point of view, the total supply of offsets by a certain date is therefore stochastic.

Uncertainty also applies to the demand side for offsets. Even when assuming that EU ETS firms would use their full import limit, the offset demand from entities outside the EU ETS in the context of the Kyoto Protocol is unknown ex ante. This demand depends on the difference between emission targets and domestic emissions in Annex B countries of the Protocol, and since future emissions are uncertain, the total number of offsets that a country will buy to comply with its Kyoto targets is not known until after the end of the Kyoto period. Countries could surrender offsets for compliance towards their Kyoto obligations until November 2015.2

\footnotetext{
${ }^{2}$ Countries' emissions during a calendar year are not made publicly available until the various sources have been
} 
We develop a model that expresses the offset price as an average of the EUA price and an offset's outside value, weighted by the probability that the import limit turns out not to be binding. We also use an alternative model that places fewer assumptions on the determination of the CER price, but which includes additional variables that are likely to be associated with offset demand.

An important part of our model is the assumption that the time delay between the initial project proposal and the eventual delivery of certified offsets breaks the short-term link between the price and the supply of offsets. For example, an increase in the offset price in 2010 may lead to more projects being initiated, but it most likely has no effect on the number of offsets generated through 2012 . Conversely, projects that are well under way and thus have incurred most of the associated fixed costs will continue to deliver offsets even if the offset price decreases, provided that the marginal costs of offset production are sufficiently low. ${ }^{3}$ The expected excess supply of offsets is then exogenous rather than jointly determined with the offset price, and can thus be used as an explanatory variable.

We estimate our models using market prices for EUAs, CERs and information about expected offset supply and demand, and find evidence for our theory of CER price formation, and thus for the determination of the EUA-CER price spread. Importantly, our model explains the gradual reduction of the CER price towards zero towards the end of 2012, implying that the offset price was indeed mostly driven by the price for EUAs, rather than the marginal abatement cost of projects of the Kyoto flexible mechanisms.

Our proposed price mechanism and existing explanations are not mutually exclusive, and we do not argue that that transactions costs play no role in CER price formation. In fact, we find evidence for the presence of informational frictions related to offset import rules, which is a type of transaction cost (although unrelated to trading or producing offsets). Although the maximally allowable number of Kyoto offsets that could be used in the EU ETS was initially defined for use during Phase II only, the EU decided in 2009 to allow firms to transfer any unused import limits from Phase II into Phase III (European Union, 2009). In theory, the relevant quantities of offset demand and supply thus became those allowed for use by 2020. However, we find that the CER price continued to be mostly driven

checked and verified, which often results in the publication of annual emissions not before the end of the following year. The deadline for purchasing offsets was set by the end of the "true-up period", which was on November 18, 2015; see the United Nations Framework on Climate Change, "True-up period reporting and review process", available at http://unfccc.int/kyoto_Protocol/true-up_process/items/9023.php, last accessed on January 15, 2016.

${ }^{3}$ Many offset projects consist in setting up new production technology, which implies a combination of high fixed costs and low (or even negative) marginal abatement costs. In other words, once a more efficient machine has been built, it will be used independently of the CER price. Naturally, this assumption does not apply to CERs that are produced by means of fuel switching; in a robustness check, we remove these projects from our analysis. 
by the expected excess supply by 2012 until much later. Our results imply that the change in offset import rules was not internalized immediately, but only with a delay of around two years, which suggests a significant departure from the assumption of an informationally efficient market.

The next section provides some more background; section 3 contains our theoretical model; section 4 presents the data and the results; and section 5 concludes.

\section{Background}

In the following, we present more information about the Kyoto flexible mechanisms and the EU's "Linking Directive" that established a link with the EU ETS, and present a short review of the literature that is concerned with the market for Kyoto offsets.

\subsection{The Kyoto flexible mechanisms}

The Kyoto Protocol's flexible mechanisms were designed to lower the cost of achieving the emissions reductions agreed to by the countries listed in Annex B (i.e., the countries that agreed to binding emissions reductions), by carrying out emissions-reducing projects more cost-effectively in other countries. The Kyoto Protocol differentiates between two types of flexible mechanisms based on where the emissions reductions take place. Projects in developing countries are governed by the Clean Development Mechanism (CDM) and produce one Certified Emissions Reduction (CER) per avoided metric ton of $\mathrm{CO}_{2}$. Emissions reductions in other Annex B countries fall under the flexible mechanism called Joint Implementatin (JI), and result in the issuance of an Emissions Reduction Unit (ERU) per metric ton of $\mathrm{CO}_{2}$. CERs and ERUs therefore only differ in terms of their origin, but not in terms of their "content" or the way they can be used, and we therefore refer to both as "Kyoto offsets" or simply offsets. The prices for CERs and ERUs were largely identical, although the market for the former was much more liquid than that of the latter; a graph of the CER and ERU prices is shown in Figure A1 in the Appendix. The price convergence is consistent with our model, in which the price for offsets is determined by their value of their use rather than their marginal cost of production, which likely differs between Annex B and developing countries.

CDM project activities have to comply with the requirements defined by the United Nations Framework Convention on Climate Change (UNFCCC, 2015a). They have to follow a seven-step 
process, which is illustrated in Figure 2.

The first step consists in the project participants (i.e., the entity that proposes to carry out the actual project) preparing a project design document (PDD) in accordance with guidelines laid out in UNFCCC (2015b), and submitting it to the Designated National Authorities (DNA) of both countries involved (i.e., the country of the project participant, and the country where the project is to be implemented). The PDD describes the proposed project and lists the expected emissions reduction per year of operation. The preparation of the PDD can be the most time-consuming step in the entire project cycle (UNFCCC, 2013).

Figure 2: CDM project cycle

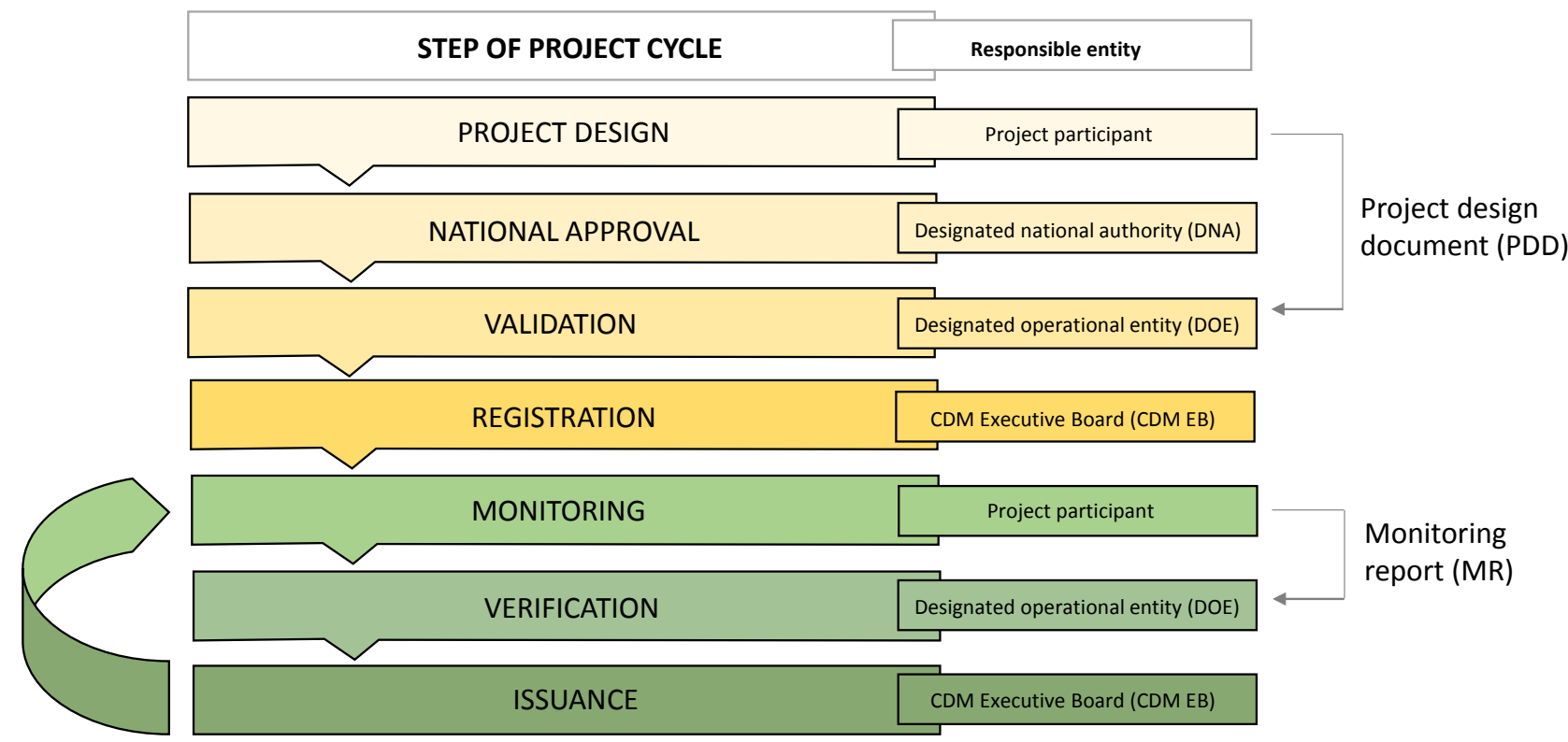

Source: Own illustration based on Fig. 3.1 in UNFCCC (2013)

If satisfied, the DNAs write a letter of approval confirming that both parties are part of the Kyoto Protocol, and that the project contributes to the host country's sustainable development. Based on this national approval, the project participants then contract an independent auditor, a so-called designated operational entity (DOE) for the validation of the project activity. $]^{4}$ The DOE verifies whether the project proposal is consistent with the requirements of the CDM according to additionality and other

\footnotetext{
${ }^{4}$ Firms or organizations have to be registered by the UNFCCC in order to become DOEs. The Executive Board of the Clean Development Mechanism (CDM EB) maintains a public list of approved DOEs.
} 
requirements defined in UNFCCC (2015bc), and makes the PDD publicly available for a 30-day consultation period. Based on the comments from the various stakeholders, the DOE either validates (i.e., approves) or rejects the project. If the project has been validated, the DOE submits a request for registration. After an additional check for completeness by the UNFCCC secretariat, the request is made publicly available. If no review request is received within 28 days, the CDM EB registers the proposed project; otherwise, and additional review takes place. All CDM projects must be registered before they can be implemented.

After the implementation of the project, the project participants have to prepare a monitoring report (MR) at regular intervals that demonstrates the emission reduction achieved, and submit it to a DOE for verification 5 The DOE verifies whether the reported emission reduction took place, based on the requirements for additionality defined in UNFCCC (2015c) and an on-site inspection. If the MR has been verified, the DOE submits a request for issuance of CERs to the CDM EB. This request is again made publicly available. If no review request is received from any party involved in the project within 28 days, the CDM EB grants the issuance of CERs according to the number of verified emission reductions. The last three steps are repeated for the duration of the project.

At each step of the CDM project cycle, a project may be rejected, or approved subject to additional requirements, which may cause a significant delay (Trotignon and Leguet, 2009). Furthermore, the number of CERs produced per year may be smaller or greater than the emissions reductions specified in the original PDD. The United Nations Environment Programme maintains a database of all CDM projects and tracks their progress that have been approved by the DNA; this monthly database is the source for our offset supply data..$^{6}$ The total time between the initial project idea and the eventual delivery of CERs depends on the nature of the project and the involved countries. The average time lag between the comment period (during validation) and the registration of a project is shown in Figure A2 in the Appendix, and Figure A3 presents the average time lag between the end of the monitoring period and the issuance of CERs. The total time it takes to "create" a CER is the sum of the time lags shown in these figures, plus the time it takes to create the PDD (anywhere between 6 months and several years) and to obtain the letters of recommendation (no data available), plus the monitoring period (usually a year), which can easily add up to 5 or more years in total. This implies

\footnotetext{
${ }^{5}$ The DOE contracted for the verification of the achieved emission reductions usually differs from the DOE contracted for validation, but the same DOE can be contracted upon request.

${ }^{6}$ The "UNEP DTU CDM/JI Pipeline Analysis and Database" is maintained by Jørgen Fenhann and is available at www.cdmpipeline.org.
} 
that the supply of CERs cannot increased in response to an increase in the CER price, at least not in the short to medium run.

Figure 3: Cumulative number of projects at different stages of the CDM cycle

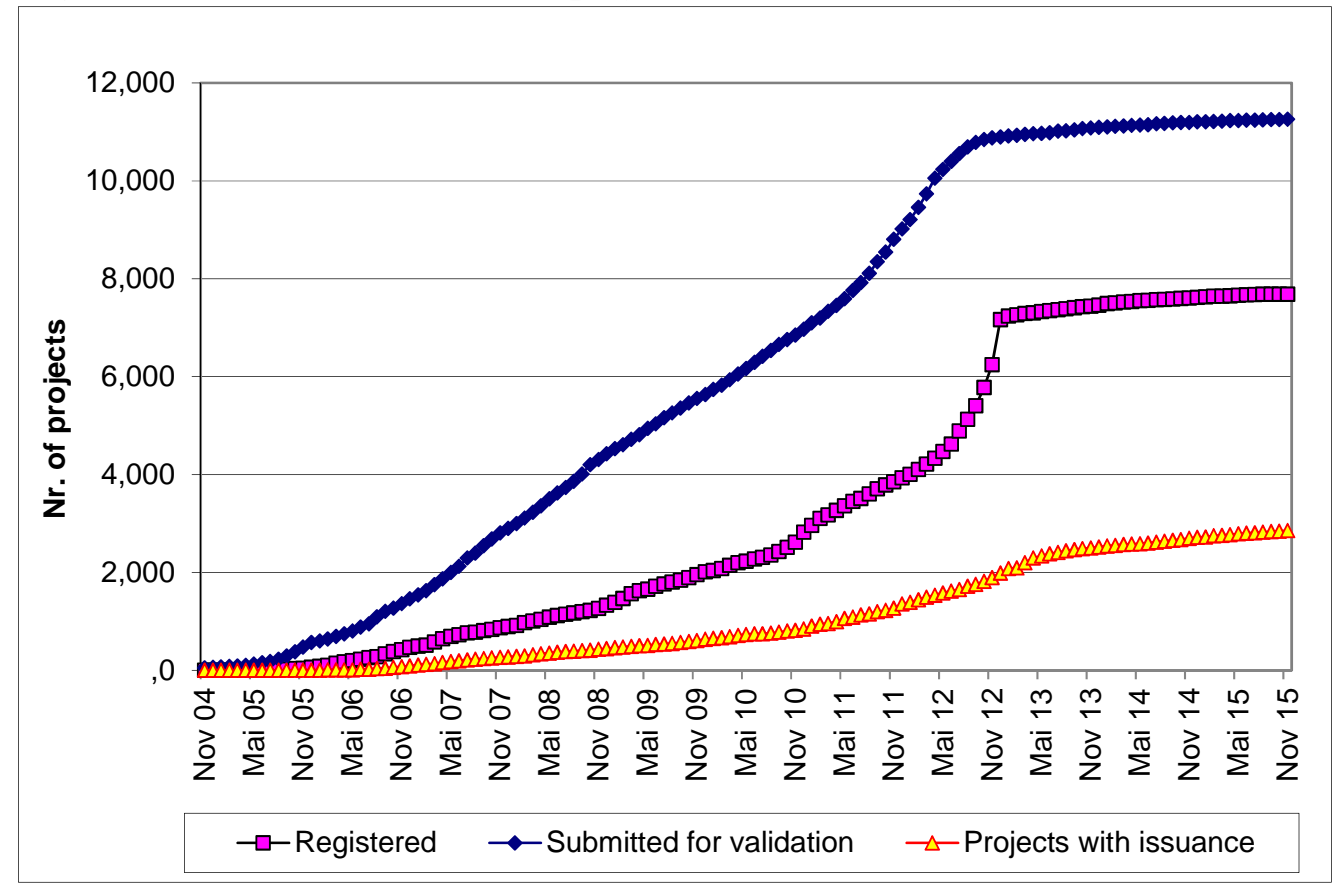

Source: United Nations, CDM pipeline from December 2015

The procedures governing Joint Implementation are very similar to those for CDM, with the main difference being that two Annex-B countries are involved. More details about JI are provided in the Appendix.

\subsection{The "Linking Directive"}

In the directive that set up the EU ETS, the European Commission allowed the included firms to cover some of their emissions using Kyoto offsets (European Union, 2003). On average, the number of Kyoto offsets that firms in the EU ETS were allowed to use was $13.5 \%$ of their free allocation, which amounted to around of 1.4 billion during Phase II. However, the exact number of offsets that could be used by firms varied by country, and sometimes even by industry. There were also differing rules regarding the use of the import quotas: Whereas some countries allowed their firms to use their quota at any time during Phase II of the EU ETS, which coincided with the period of the Kyoto Protocol, others stipulated that unused limits in one year cound not be transferred to another year.

Because of the time delays discussed above, few offsets were available in the beginning of the phase, and it was not clear how many offsets would be available by the end of 2012. To accommodate 
these issues, the European Commission decided in April, 2009, that firms could transfer any unused import limits to Phase III of the market (European Union, 2009). In addition, installations that for some reason were not given an import limit of $13.5 \%$ of free allocation in Phase II, or that entered the market only in Phase III, were given an additional import allowance for Phase III, which roughly amounted to another 300 million offsets. The total number of offsets that EU ETS firms are allowed to use between 2008 and 2020 is therefore around 1.7 billion.

Offsets generated during the Kyoto period could be banked for use after 2012. However, the reverse was not true: Offsets generated after 2012 could not be used for compliance in Phase II. 7 However, because of the large amount of banked EUAs and the right to use up import limits during Phase III, this no-borrowing constraint was not binding.

Offsets generated after 2013 could be used by EU ETS firms, but with some restrictions regarding the activities and locations of projects. Specifically, activities involving HFC-23 and nitric acid were excluded, and projects had to be located in a "least developed" country.

\subsection{Related literature}

Contributions to the literature on CERs and/or the relationship of the prices of which to EUA prices fall broadly into three categories. The first category includes non-theoretical time series models. Nazifi (2013), for instance, puts forward the notion that assuming a fixed structural relationship between EUA and CER prices is not appropriate. In consequence, she employs a time-varying parameter model. As discussed above, among the main findings of that paper is that EUA price drivers affect CER prices in a different way and, as a result, a price spread emerges. An additional example for this group is Koop and Tole (2013), who employ flexible multivariate timeseries models to allow for time-varying parameters in order to study in order to jointly model EUA (spot as well as futures) and CER prices. This paper provides evidence for contemporaneous causality with a dominant role of EUA futures, and furthermore shows that the relationship between these price series is changing over time due to the influence of macroeconomic factors such as the financial crisis. Qualitatively similar findings are obtained by Chevallier (2012), who uses a regime-switching model to show that business cycles are an important driver of the dynamics of the relationship. Mansanet-Bataller et al. (2011), finally, show that a cointegration relationship exists between EUA and CER prices with a dominant

\footnotetext{
${ }^{7}$ This could theoretically have been the case for offsets generated between January and April of 2013, as this is the time when firms had to surrender allowances to cover their emissions for the year 2012.
} 
role of the former. A VAR based variance decomposition analysis confirms this result: a significant share of the variation of CER prices is explained by EUA price variations.

The second category includes structural analyses. Kanamura (2016) studies the influence of carbon swap trading as well as energy prices in the relationship of EUA and CER prices and reports that the correlation between EUA and CER prices has different drivers in different periods: while EUA-CER swap transactions explain a high correlation during periods with high EUA prices, falling energy prices explain the correlation between the two price series in the period of the financial crisis. Whereas the studies summarised so far are concerned with the price behavior, Hieroymi and Schüller (2015) investigate how the existence of different emission permit classes affects energy investments. The authors apply a real options approach as they assume that permit prices are uncertain. They find that the possibility of using offsets indeed has an effect on investment decisions. Among additional influence factors are found to be interest rates and volatility.

The third and last category of papers consists of investigations of the CDM as such. Rahman and Kirkman (2015), for instance, examine the costs of certified emissions reductions and find that they decrease with project scale and duration, and furthermore vary significantly across project types. Finally, evidence of an upward trend in cost is found. Trotignon (2012) provides an overview of the regulatory conditions and analyses the use of offsets in the EU ETS in 2008 and 2009. The article finds that some ETS firms used offsets during the first two years of Phase II, but that many firms did not. Among the offset importers, very few used up their import limits. One of the key issues the paper addresses is the role of transaction cost. Braun et al. (2015) set up a model where multiple compliance targets co-exist, and show how transactions costs lead to a price spread between otherwise identical emission allowances.

\section{Model}

In the following, we present the models we use to analyze the determinants of the EUA-CER spread. We start with our base model, followed by a model extension that places fewer restrictions on price determination. As our final model, we drop any theory of CER price determination and test for the existence of a common trend using a cointegration approach. 


\subsection{Theory}

We denote EUA prices by $P_{t}$, with $t \in[0, T]$ and $T$ referring to the final period. Similarly, $C_{t}$ refers to the price for offsets from the Kyoto flexible mechanisms (either CERs or ERUs). Global demand and supply of offsets at time $t$ are given by $d_{t}$ and $s_{t}$, respectively. We assume that the probability of noncompliance (i.e., that total emissions during Phase II exceed total allocation plus the import limit) is negligible, which was arguably the case after the decrease in business-as-usual emissions in the wake of the economic crisis of 2009. This means that a positive amount of allowances is transferred from Phase II to Phase III, which in turn implies that the allowance price in these two phases is continuous. This assumption is consistent with the empirical price data.

We denote $S_{0}^{t} \equiv \sum_{k=0}^{t} s_{k}$ as the cumulative offset supply by time $t$, which is observable, and $S_{t}^{T} \equiv \sum_{k=t+1}^{T} s_{k}$ as the cumulative future offset supply until the terminal period, which is uncertain at time $t$. Likewise, let $D_{0}^{t} \equiv \sum_{k=0}^{t} d_{k}$ refer to cumulative offset demand observed to date, and $D_{t}^{T} \equiv \sum_{k=0}^{t} d_{k}$ to uncertain future demand. We assume that both offset supply and global demand are treated as pre-determined by market participants, rather than a function of the prices for offsets and/or EUAs. The rationale for this assumption on the supply side is the long time period between planning a project and the delivery of verified offsets. Even though high prices could trigger additional investment, the additional offsets would not be available for several years. On the demand side, Annex B countries typically make their purchases depending on the success of their domestic abatement efforts, which are independent of the price of offsets 8

As long as offsets can be used in the EU ETS, the relevant opportunity cost is the price of an EUA: Buying one offset allows firms to save one EUA to cover their emissions, which they can either sell on the market or bank into future periods $t>T$. If the EU ETS import limit has been reached, the opportunity cost for an offset depends on the willingness to pay by Annex B countries to reduce their Kyoto compliance gap by one unit, which could in theory be different to the price for EUAs. However, for lack of a different global reference price for $\mathrm{CO}_{2}$ emissions, and because countries could also use EUAs in lieu of offsets to comply with their Kyoto obligations, we assume that the WTP for offsets both within and outside the EU ETS is given by the price for an EUA as long as the total number of supplied offsets does not exceed global demand related to the Kyoto process.

\footnotetext{
${ }^{8}$ At very high offset prices, countries might prefer to institute new climate policies. However, the time lag between the proposition of new policy and results in terms of abatement may take years as well. In any case, the prices of offsets were below expectations throughout the Kyoto Phase, and certainly well below abatement costs e.g. by fuel switching.
} 
If supply exceeds global demand (i.e., demand from the EU ETS plus Annex B countries), the WTP for offsets will be related to their use in the context of a future climate agreement. Denoting the value for this "residual" use assigned to offsets at time $t$ as $V_{t}$, we obtain the following relationship between offsets and EUA prices in some terminal period T:

$$
\begin{aligned}
& C_{T}=P_{T} \quad \text { if } \quad S_{0}^{T} \leq D_{0}^{T} \\
& C_{T}=V_{T} \quad \text { if } \quad S_{0}^{T}>D_{0}^{T}
\end{aligned}
$$

At time $t<T$, firms are not sure whether offset supply will exceed global demand. The expected payoff from holding an offset at time $t$, subject to the available information at this time, is

$$
E_{t}\left[C_{T}\right]=E_{t}\left[P_{T}\right] \cdot \operatorname{Pr}\left(S_{0}^{t}+S_{t}^{T} \leq D_{0}^{t}+D_{t}^{T}\right)+E_{t}\left[V_{T}\right] \cdot \operatorname{Pr}\left(S_{0}^{t}+S_{t}^{T}>D_{0}^{t}+D_{t}^{T}\right)
$$

Let $x_{t} \equiv S_{t}^{T}-D_{t}^{T}$ refer to future cumulative excess supply between $t$ and the final period, which is a stochastic variable distributed according to the probability density function $f\left(x_{t}\right)$. This allows us to express (3) as

$$
E_{t}\left[C_{T}\right]=E_{t}\left[P_{T}\right] \cdot \int_{-\infty}^{D_{0}^{t}-S_{0}^{t}} f\left(x_{t}\right) d x_{t}+E_{t}\left[V_{T}\right] \cdot \int_{D_{0}^{t}-S_{0}^{t}}^{\infty} f\left(x_{t}\right) d x_{t}
$$

Using the central limit theorem and defining the expectation and standard deviation of $x_{t}$ as $\mu_{t}^{x}$ and $\sigma_{t}^{x}$, respectively, the variable $Q_{t} \equiv\left(x_{t}-\mu_{t}^{x}\right) / \sigma_{t}^{x}$ has a standard normal distribution such that we can express (4) as

$$
E_{t}\left[C_{T}\right]=E_{t}\left[P_{T}\right] \cdot \Phi\left(\frac{D_{0}^{t}-S_{0}^{t}-\mu_{t}^{x}}{\sigma_{t}^{x}}\right)+E_{t}\left[V_{T}\right](1-\Phi(\cdot))
$$

where $\Phi(\cdot)$ refers to the cumulative density function of the standard normal distribution, and its argument $\Phi(\cdot)$ is the standardized expected excess demand until period $T$.

Arbitrage implies that the prices of offsets and EUAs have to be equal to their discounted expected prices in period $T$ :

$$
C_{t}=P_{t} \cdot \Phi\left(\frac{D_{0}^{t}-S_{0}^{t}-\mu_{t}^{x}}{\sigma_{t}^{x}}\right)+e^{-r(T-t)} E_{t}\left[V_{T}\right] \cdot(1-\Phi(\cdot))
$$


Eq. (6) states that the price of an offset is equal to the price of an EUA, times the probability that the total supply of offsets is insufficient to cover the total offset demand from EU ETS firms and Annex B countries. In that case, offsets and EUAs are fungible assets and their prices converge. If, on the other hand, the market expects an oversupply of Kyoto offsets, then offsets should trade at a significant discount relative to EUAs, assuming that $E_{t}\left[V_{T}\right]<P_{t}$. If there is no use for Kyoto offsets outide of the Kyoto Protocol and the EU ETS, then $V_{T}=0$.

\subsection{Econometric model}

In our data, we do not observe $D_{0}^{t}$ and $D_{t}^{T}$ separately and thus cannot compute $\mu_{t}^{x}$ directly. However, the numerator in (6) is the total expected excess demand, which we can compute by

$$
D_{0}^{t}-S_{0}^{t}-\mu_{t}^{x}=E_{t}\left[D_{0}^{t}+D_{t}^{T}\right]-E_{t}\left[S_{0}^{t}+S_{t}^{T}\right] \equiv \varphi_{t}
$$

There is no empirical information about what $\sigma_{t}^{x}$ should be. But if only few offsets have been issued, the uncertainty associated with delays and attrition is arguably greater than if a larger share of the announced offsets already exists. We therefore specify the uncertainty about future excess supply as a decreasing function of the share of announced offsets that have actually been issued by time $t$, and include $\sigma$ as a free parameter in the model:

$$
\sigma_{t}^{x}=\sigma \cdot \frac{S_{0}^{t}+E\left[S_{t}^{T}\right]}{S_{0}^{t}} \text { for } \quad S_{0}^{t}>0
$$

The parameter $\sigma$ represents the standard deviation of the expected excess supply if all announced offsets have been issued; the resulting uncertainty is therefore entirely due to the demand side.

Last, (6) depends on market participants' expectation of the outside value of offsets, $V_{T}$. We leave this as a free paramater, but allow it to be updated once after the Copenhagen talks failed; in some specifications, we allow it to be updated yearly. 9

As discussed above, we assume that the demand and supply of offsets is independent of its price in the medium term, which allows us to use excess demand as an exogenous regressor. Previous research

\footnotetext{
${ }^{9}$ In December 2009, it became clear that there would be no continuation of the Kyoto Protocol in the sense that there was no binding multinational treaty that specified mandatory emissions reductions. However, some countries (including all members of the EU) agreed to voluntary emissions reductions. However, the Copenhagen talks were not the only "news" to affect market participants' beliefs in the value of offsets outside the EU ETS; with our annual updates, we try to capture these informational updates.
} 
has shown (and we confirm this below) that the prices for EUAs and CERs are cointegrated, but that the former drives the latter. This is consistent with our theory that the CER is priced according to its substitution possibility for EUAs. However, this unidirectional“Granger”-causality does not precluce the possibility that the two carbon prices are affected jointly by contemporaneous shocks. In order to reduce the scope for endogeneity, we include the EUA price in lagged form. This leads us to the following regression specification:

$$
C_{t}=\alpha \cdot P_{t-1} \cdot \Phi\left(\frac{\varphi_{t}}{\sigma \cdot E\left[S_{0}^{T}\right] / S_{0}^{t}}\right)+e^{-r(T-t)}\left[V_{0}+V_{Y} \cdot Y D_{t}\right] \cdot(1-\Phi(\cdot))+\epsilon_{t}
$$

Here, $Y D_{t}$ is a vector of yearly dummies, and $\epsilon_{t}$ is white noise. We include the parameter $\alpha$ to allow for the possibility that our model does not capture the full price determination process. Intuitively, one might think that the natural null hypothesis implied by our model is that $\alpha=1$, but this is not quite correct because we include the lagged rather than the current allowance price, such that $\alpha$ also captures the correlation coefficient between current and lagged prices. We therefore confine ourselves to the null hypothesis of $\alpha>010$ The parameters to estimated (by nonlinear regression) are $\alpha, \sigma, V_{0}$ and the vector $V_{Y}$, which contains as many parameters as dummies are included in $Y D_{t}$.

Last, the time period $T$, to which demand and supply of offsets is measured enters the model via $\varphi_{t}, E\left[S_{0}^{T}\right]$, and the discount factor. If market participants incorporated all relevant information immediately, the relevant time Horizon would be December 2012 in the beginning, but switch to December 2020 when the EC decided to allow for the transfer of any unused import limits to Phase III. However, we do not want to impose complete information and full market efficiency, but rather test for the moment when market participants switched from considering December 2012 to December 2020 as the relevant time horizon. To do this, we estimate (9) for all switches in the relevant time horizon' between April 2009 (when the decision to transfer the import limit was made) and December 2012 (as it would make little sense to consider December 2012 as the relevant time horizon after that). We define the "revealed switching month" as the switching month that provides the best model fit.

\footnotetext{
${ }^{10}$ Note that a simple IV approach to recover the coefficient on the current allowance price (multiplied by the probability expression) is not possible due to the nonlinearity of the problem.
} 


\subsection{Alternative specification}

Specification (6) is quite restrictive to explain the CER price in the sense that it assumes that market participants are well informed about the regulatory link between the EU ETS and the market for offsets. It furthermore assumes that all relevant information about offset demand and supply is captured by $\varphi_{t}$. Whereas there is detailed information about offset supply, the information on the demand side is much less complete (see below).

To accommodate these concerns, we use an alternative model, which follows less from theory and is therefore more ad-hoc than (6), but which imposes fewer restrictions on the data and market participants' level of information. Specifically, we express the CER price as

$$
C_{t}=\beta_{0}+\beta_{1} \cdot P_{t-1}+\beta_{2} \cdot \varphi_{t}+\beta_{3} \cdot\left(P_{t-1} \cdot \varphi_{t}\right)+\beta_{4} \cdot F_{t}+\beta_{5} \cdot\left(F_{t} \cdot P_{t-1}\right)+\Gamma \cdot Y D_{t}+u_{t}
$$

Here, the CER price is a function of the (lagged) allowance price, excess offset demand, the FTSE market index for Europe (represented by $F_{t}$ ), and interaction terms between the allowance price and the other two variables. The FTSE is a measure for economic activity and is thus a proxy for offset demand by European countries in the context of the Kyoto Protocol.

According to our theory developed above, the allowance price should influence the CER price to the extent that CERs can be substituted for EUAs, but not independent of this probability. In the context of $(10)$, this implies the null hypotheses of $\beta_{1}=0, \beta_{3}>0$. Likewise, excess demand for offsets should influence the CER price only via the EUA price but not directly, such that our theory implies that $\beta_{2}=0$. If the FTSE contains relevant information about offset demand that is not already captured by $\varphi_{t}$, but only affects the CER price via the EUA price, then we expect that $\beta_{4}=0, \beta_{5}>0$

\subsection{Test for cointegration}

In addition to the models presented above, we additionally employ a traditional cointegration test in order to investigate the EUA-CER price relationship, a methodology also used by Mansanet-Bataller et al. (2011). This procedure captures the theoretical models put forward in a different manner. If the probability that a CER can be substituted for an EUA at the end of the relevant time period is high, the two price series would be closely related and, thus, possibly cointegrated. In contrast, the smaller this probability is, the less related the prices will be, which should result in no cointegration. 
Rather than testing whether or not a cointegration relationship exists over the entire sample, we investigate how this this relationship changes over time. To do this, we start with an initial subsample and subsequently add observations, while holding the beginning of the sample fixed ${ }^{11}$ For each of these subsamples, we perform a standard Engle-Granger test for cointegration. This so-called single equation cointegration test has been put forward by Engle and Granger (1987). The null hypothesis of no cointegration is tested as follows: initially, the EUA price is regressed on the CER price and the residuals are calculated. This residual series measures the distance between the two variables under consideration. If a cointegration relationship exists - or in other words, an equilibrium relationship the residual series would be stationary. A Phillips-Perron unit root test is applied in order to test the hypothesis of a unit root against a stationary alternative. A rejection of this hypothesis would imply that the residuals are stationary and, thus, a cointegration relationship exists. The foreward-recursive application of this procedure yields a sequence of $\mathrm{p}$-values, which can then be used to illustrates a potential change in the cointegration relationship over time.

\section{Data}

In this section we describe our data and the data processing of the information in the CDM/JI pipeline.

\subsection{Offset supply}

We obtained a monthly series of the UN's "CDM and JI pipeline" ${ }^{12}$ The data contains information about all projects that have reached at least the validation stage. For each project, the expected number of offsets is computed by the end of 2012 and by the end of 2020 . The data also contains information about actual offset issuance, project type, location etc.

The expected number of offsets is based on the information contained in the project design document (PDD). To correct for delays and to incorporate new information about the issuance success (i.e., the productivity) of a project, we make the following corrections:

\footnotetext{
${ }^{11}$ This procedure is referred to as "foreward recursive" and is very common in the applied time series literature. Most recently, Phillips and $\mathrm{Yu}$ (2011) employ this procedure in order to identify origin and collapse date of stock market bubbles. This further development of so-called cointegration based tests for speculative bubbles also involves applications of unit root tests.

${ }^{12}$ Available at www.cdmpipeline.org, last accessed in January 2016. The website only contains the current pipelines. We thank Jorgen Fenhann for providing us with the historic pipelines.
} 


\section{Credit start of projects that have not yet been registered}

The PDD of each project contains an expected credit start, which is the expected time when a project starts to actually reduce emissions and thus generates emission offsets. This credit date is only adjusted if a revised PDD is submitted, or if the project is registered. Due to delays in the CDM or JI process (see above), the projected credit start is quite often before the current month of observation, even though the project has not yet been registered (and thus the credit start cannot have happened). Whenever this is the case, we replace the expected project date with the current date. For example, suppose that the CDM pipeline of July 2011 lists an unregistered project with a projected credit start in 2010. In this case, the expected project start is moved forward to July 2011.

\section{Issuance success of registered projects}

Once a project is registered, it begins to produce offsets. After each monitoring period, the number of generated offsets during this period is listed in the (verified) monitoring report. This number may be greater or smaller than the number expected based on the PDD due to unforeseen shocks or events; however, the "expected offsets by 2012/2020" series in the CDM and JI pipelines do not account for this new information, but continue to list the expected offsets based on the PDD. To correct for the heterogeneity in issue success, we adjust the number of expected offsets using the information in the following way:

Corrected expected (exp.) issuance (iss.) by $T=$

$$
\text { (Exp. iss. by } T-\text { Exp. iss. by } \bar{t}) \cdot\left(\frac{\text { Observed iss. by } \bar{t}}{\text { Exp. iss. by } \bar{t}}\right)+\text { Observed iss. by } \bar{t}
$$

For example, suppose that a project started in 2009, and based on its PDD it is expected to deliver 250,000 offsets per year, or 1 million offsets by the end of 2012. However, the monitoring report for the first year $(\bar{t}=$ December 31,2009$)$ shows that instead of the projected 250,000, only 200,000 offsets were produced. The formula above then computes the corrected expected issuance using this issuance success of $80 \%$, which results in a corrected expected issuance of $(750 \mathrm{kt} \cdot 0.8+200 \mathrm{kt}=)$ $800 \mathrm{kt}$ by 2012. An equivalent correction applies to the number of expected offsets by 2020 . 
Figure 4: Expected CERs by project type

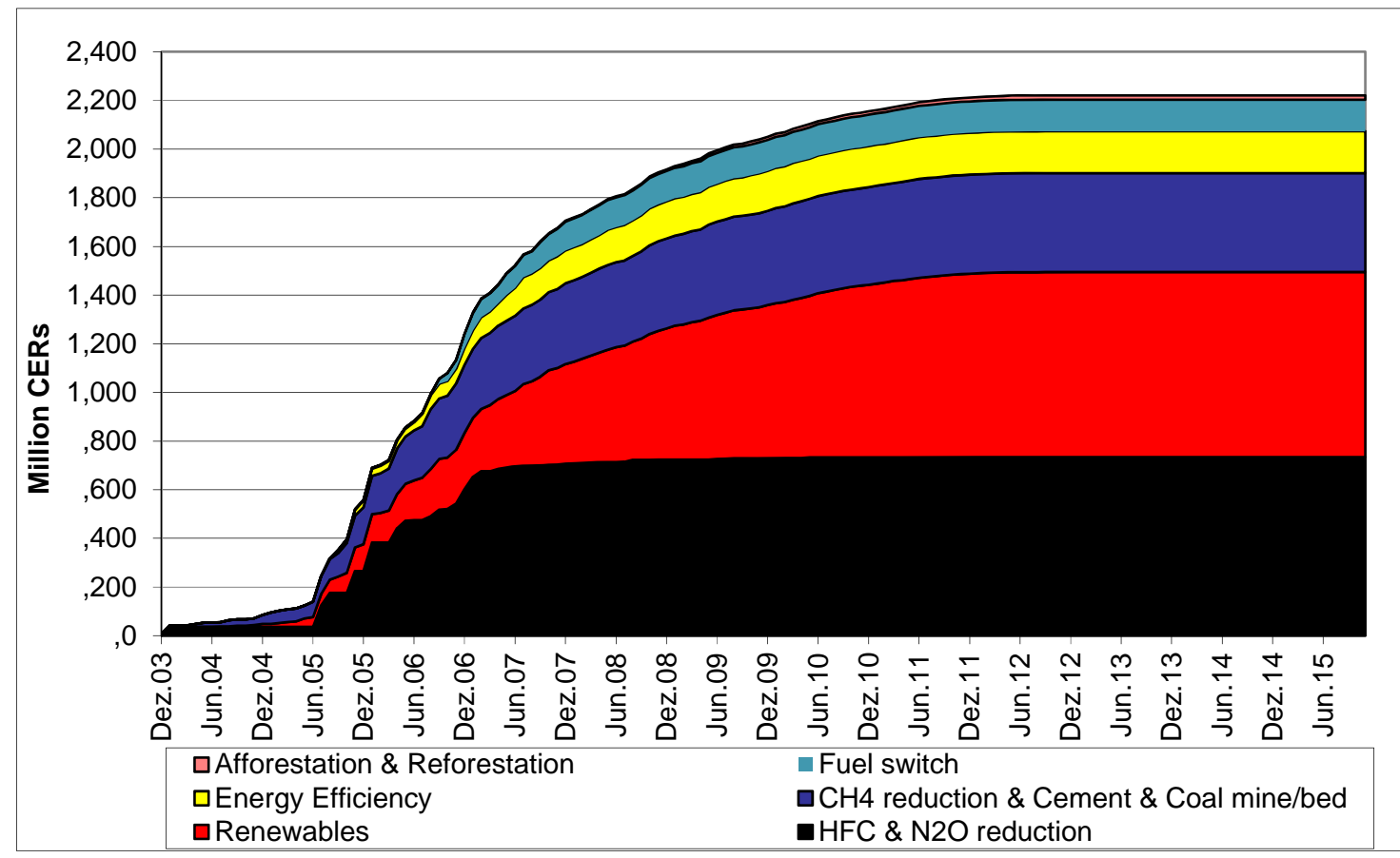

Source: CDM pipeline from December 2015, Chart 8

\section{Restrictions for Phase III}

After the end of Phase II, offsets from projects involving the reduction of HFC-23 or nitric acid were excluded for use in the EU ETS or the Kyoto market. This excluded a significant share of the expected offsets by 2020, as shown in Figure 4. Furthermore, only projects in "least developed countries" were allowed for continued use (European Union, 2009), which excluded offsets from projects e.g. in China. Issuance of CERs or ERUs from projects that did not meet these criteria was still possible, but only for the emissions reductions that took place before 2013 . We corrected the "expected by 2020" series for the Phase III-restrictions by excluding offsets that did not meet the inclusion criteria.

\subsection{Offset demand}

We obtained estimates for offset demand from Bloomberg, which cites the World Bank as one of the sources. Demand estimates are split up between demand from EU ETS firms, based on the offset import rules and Annex B countries. The data furthermore differentiate between demand by 2012, and demand by 2020. However, expectations for the latter were not updated every month, but only when new information became available. 
Figure 5 presents the the original and the corrected estimates for offset supply (sum of CERs and ERUs) by 2012 and by 2020 over time, along with the actual issuance. The drop in the supply estimates by 2020 is predominantly due to the restrictions imposed for Phase III. Figure 6 shows the expected excess demand for offsets, defined as the difference between expected demand and expected supply by 2012 and 2020. The figure shows that the time horizon considered is very important. Whereas demand and supply were similar by 2012, which made it quite possible that EUAs and CERs would turn out to be fungible assets, the surge in supply by 2020 (accompanied by a much smaller increase in demand) resulted in a significant expected excess supply.

Figure 5: Supply and demand for offsets

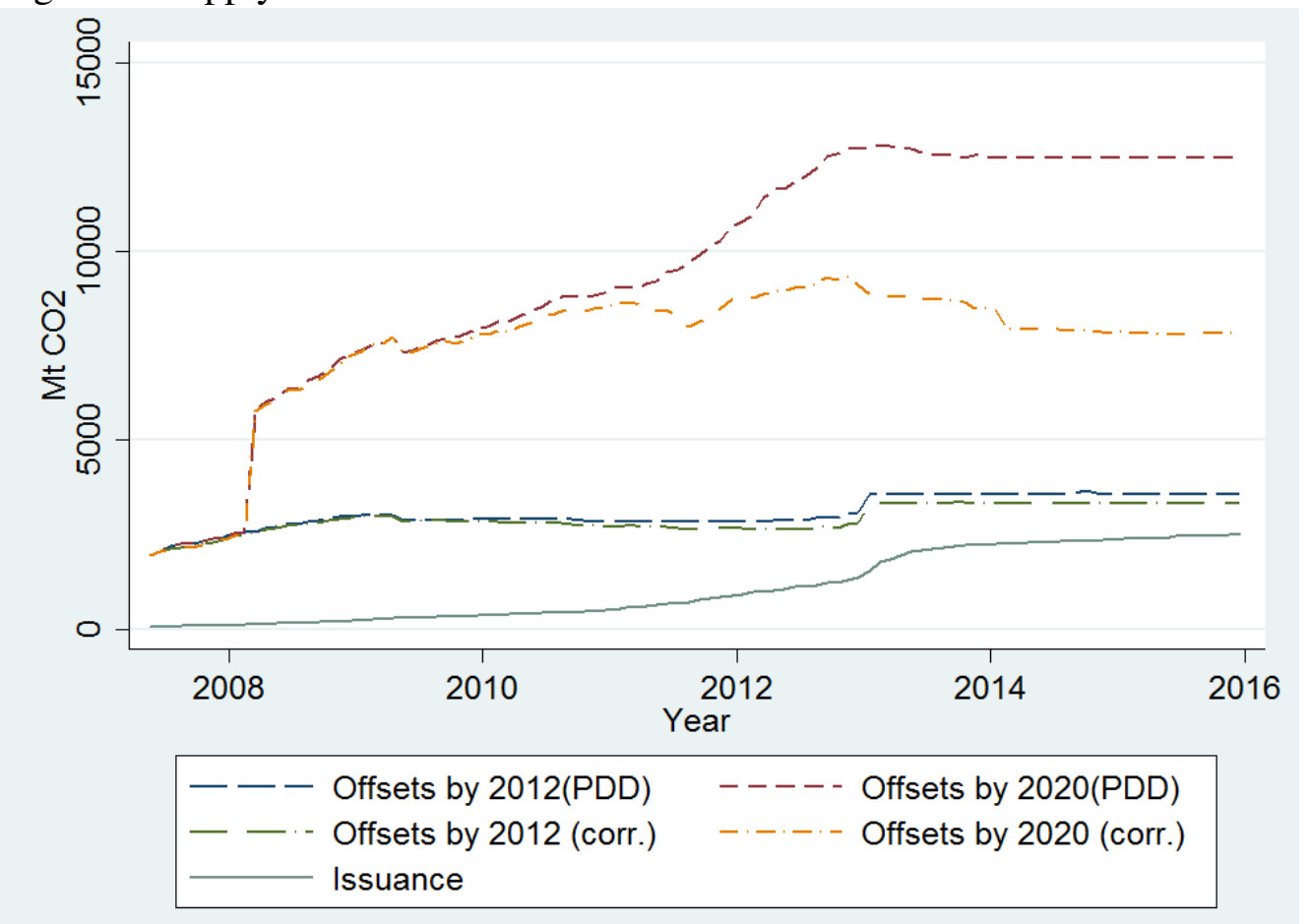

Source: Own illustration based on data from UN CDM/JI pipelines

\subsection{Exchange data}

We used next-December futures for EUAs from the European Energy Exchange (EEX). For the CER price, we use the one-year future from Nordpool until February 2008, and a broker price from Reuters thereafter (the Nordpool price series ends at some point; at the switch, the two prices are identical). We accessed these prices via Thomson Reuters Datastream, along with the time series for the FTSE Eurotop 100 and the interest rate for 10-year German government bonds.

Summary statistics of all variables are presented in Table 1 . Because the offset supply data follows 
Figure 6: Expected excess demand for offsets (demand minus supply)

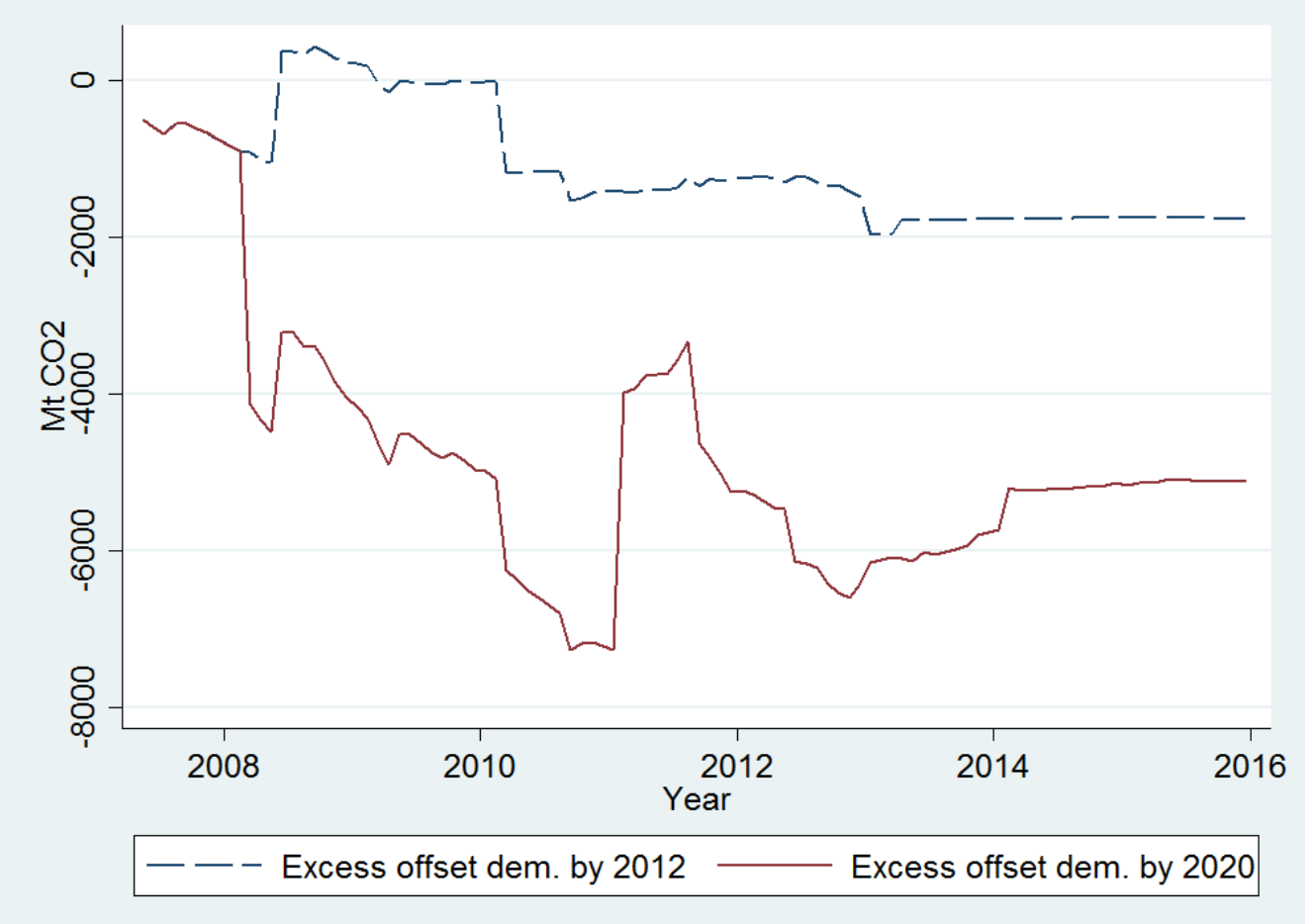

Source: Own illustration based on data from UN CDM/JI pipelines

a monthly frequency, we use monthly values for our analysis, with the exception of the cointegration tests 13

Table 1: Summary statistics

\begin{tabular}{lcccccc}
\hline Variable & Obs & Unit & Mean & Std. Dev. & Min & Max \\
\hline Offsets expected by 2020 & 103 & Mt CO2 & 2920.18 & 346.04 & 2037.00 & 3351.00 \\
Offsets expected by 2012 & 103 & Mt CO2 & 7560.85 & 1797.44 & 2037.00 & 9342.00 \\
Offset issuance & 103 & Mt CO2 & 1109.39 & 905.56 & 51.00 & 2498.00 \\
Expected demand by 2012 & 103 & Mt CO2 & 1803.13 & 616.22 & 1254.93 & 3236.74 \\
Expected demand by 2020 & 103 & Mt CO2 & 2724.10 & 812.93 & 1254.93 & 4700.00 \\
Excess demand by 2012 & 103 & Mt CO2 & -1117.05 & 712.44 & -1966.82 & 431.74 \\
Excess demand by 2020 & 103 & Mt CO2 & -4836.76 & 1606.58 & -7263.07 & -537.00 \\
CER & 103 & Euro/tCO2 & 7.57 & 6.70 & 0.14 & 21.05 \\
EUA & 103 & Euro/tCO2 & 11.86 & 6.18 & 3.55 & 27.38 \\
FTSE & 103 & (index) & 2456.93 & 418.36 & 1519.89 & 3310.83 \\
Interest rate & 103 & \% per year & 2.34 & 1.22 & 0.16 & 4.58 \\
\hline
\end{tabular}

\footnotetext{
${ }^{13}$ The cointegration tests do not include the offset supply data, and we therefore use a daily frequency. Furthermore, we start the cointegration analysis in early 2009 and use logs rather than levels; both decisions are motivated by convergence issues.
} 


\section{Results}

The first test concerns the date at which the series "excess demand by 2012 " is replaced by the series “excess demand by 2020". We vary the switching date between April 2009 and December 2012 and estimate specifications (9) (including a version where we set $\alpha=1$ ) and (10)) for every switching date. Figure 7 shows the resulting series of Bayesian Information Criterion (BIC) ${ }^{14}$ The best model fit turns to be highest if excess demand is switched to the 2020 horizon in August 2012, i.e. almost at the end of Phase II.

Figure 7: Switching from 2012 to 2020 horizon

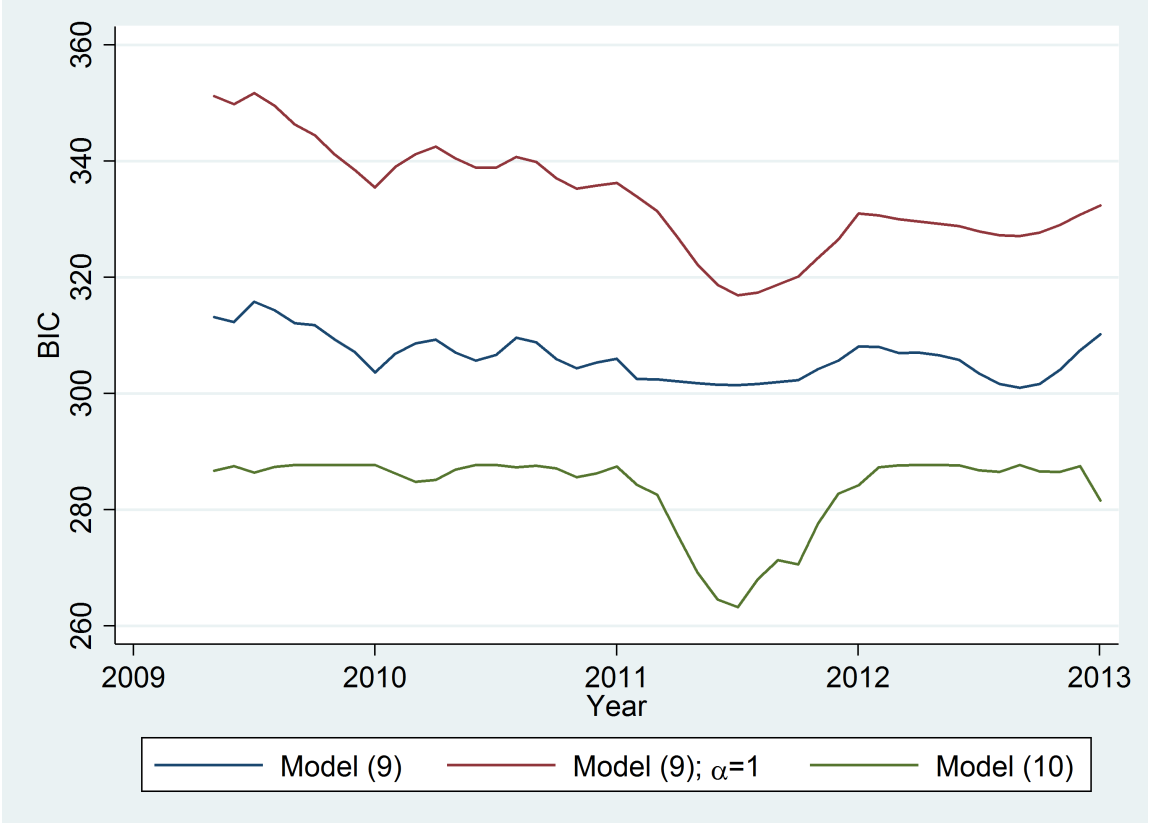

The power of this test is rather weak, as the differences in the BIC are minor especially for (9). However, our cointegration test provides additional evidence for this switching date. The results are displayed in Figure 8. Initially, there is strong evidence for cointegration between EUA and CER prices. This finding is consistent with the theoretical considerations of this paper in the sense that both prices follow a common trend. The p-values obtained from the rolling cointegration test fluctuate around $5 \%$; whereas for a small number of subsamples, we find values slightly above $10 \%$. However, once observations from the period September/October 2012 are included in the sample, the cointegration relationship collapses, and the p-values suddenly exceed conventional significance level by a wide margin 15

\footnotetext{
${ }^{14}$ Using Akaike's Information Criterion and the average absolute error leads to the same switching month, with similarly small differences.

${ }^{15}$ Note that this procedure is not sufficiently precise to detect the exact month of switching; however, cointegration breaking down once data from Fall 2012 are included is consistent with a switch in late summer of the same year.
} 
Figure 8: Cointegration test with rolling time window

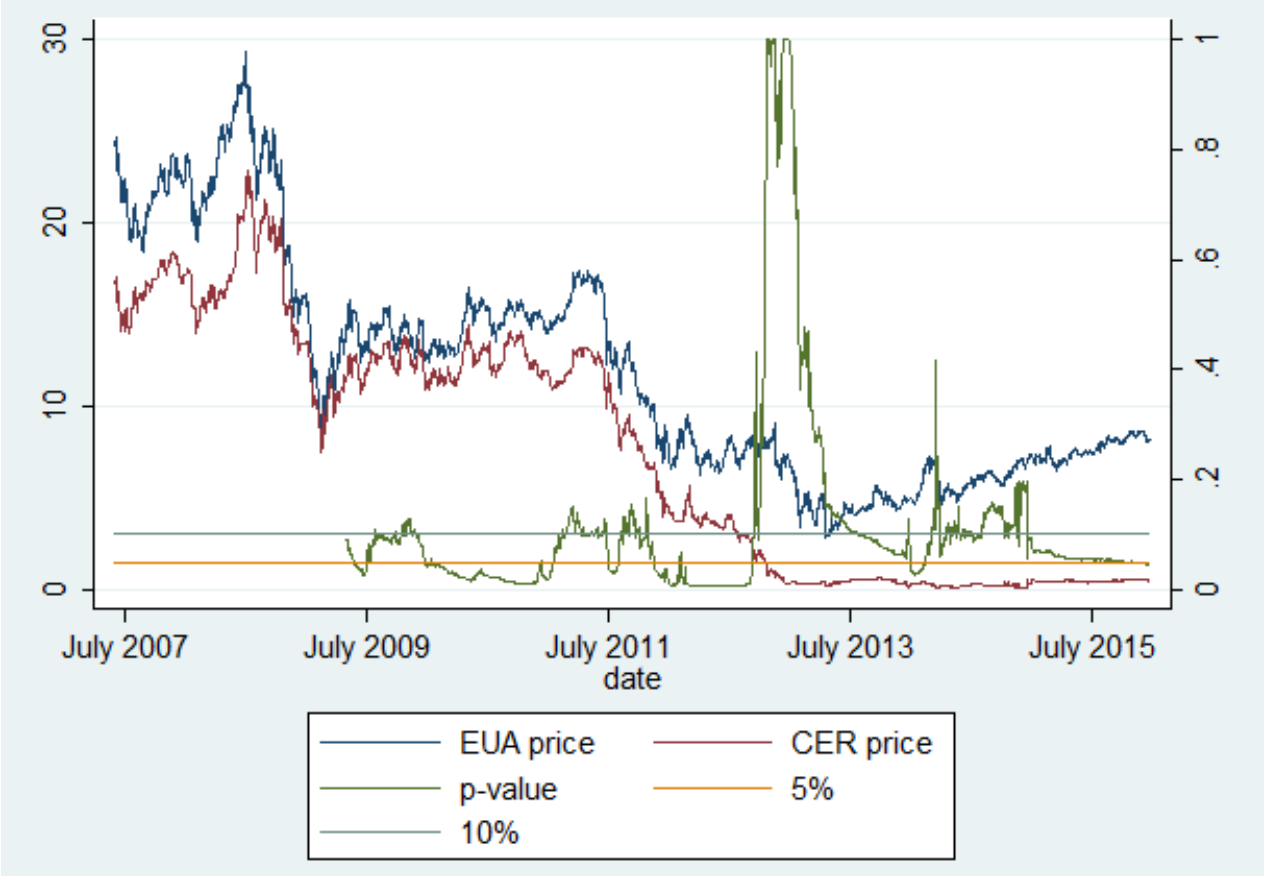

Table 2: Estimation results

\begin{tabular}{lrrrr}
\hline \multicolumn{4}{c}{ Specification (9) } & \multicolumn{2}{c}{ Specification (10) } \\
& Coef & \multicolumn{1}{c}{ Coef } & \multicolumn{1}{c}{$\mathrm{t}$} \\
\hline EUA $\cdot \Phi(\cdot)$ & 1.6138 & 19.00 & & \\
$\sigma$ & 1273.1290 & 3.38 & & \\
EUA & & & 0.5582 & 5.14 \\
$\varphi$ & & & 0.00005 & 0.23 \\
EUA $\cdot \varphi$ & & & 0.00005 & 2.39 \\
FTSE & & & 0.0009 & 1.46 \\
EUA $\cdot$ FTSE & & & 0.00004 & 0.77 \\
Y2008 & -4.2219 & -1.50 & 0.4387 & 0.66 \\
Y2009 & 8.2548 & 1.73 & 1.6327 & 1.92 \\
Y2010 & 11.0780 & 1.99 & 2.1919 & 2.59 \\
Y2011 & 5.6639 & 1.05 & 0.1544 & 0.18 \\
Y2012 & 0.8091 & 0.14 & -2.4775 & -2.48 \\
Y2013 & 2.0678 & 0.33 & -2.9191 & -2.26 \\
Y2014 & 1.7903 & 0.28 & -4.0514 & -3.20 \\
Y2015 & 1.9579 & 0.31 & -4.8434 & -3.89 \\
Cons & -2.96487 & -0.45 & 0.00000 & 0.00 \\
N & 103 & & 103 & \\
Adj. Rsq & 0.9927 & & 0.9930 & \\
BIC & 0.8617 & & 0.8457 & \\
RMSE & 300.98 & & 304.14 & \\
\hline
\end{tabular}

Note: The EUA price lagged by one period.

The estimates from estimating specifications $(9)$ and (10) are shown in Table 2 and are based on a switching date of August 2012 $\sqrt{16}$ The results in the left panel are consistent with our hypothesis that the CER is driven by the EUA price, weighted by the probability that EUA and CER turn out to be

\footnotetext{
${ }^{16}$ Changing the switching date by a few months does not qualitatively alter the results
} 
fungible assets $(\alpha>0)$. The estimate for $\sigma$ indicates that there is much uncertainty about the demand for offsets (recall that $\sigma$ is the standard deviation associated with the demand side). The regression based on (10) confirms these results in the sense that the coefficient on the interaction term between the (lagged) EUA price and excess offset demand is statistically significant and positive. However, the EUA price affects the CER price not only via its interaction with excess demand, but also directly; this is an indication that model (9) does not describe the complete price formation process, but that there other forces at play. The coefficients on the FTSE and its interaction with the EUA price are jointly significant, suggesting that the demand data for offsets included in $\varphi$ is incomplete.

Figure 9: Probability of non-binding offset limit vs. loss in cointegration

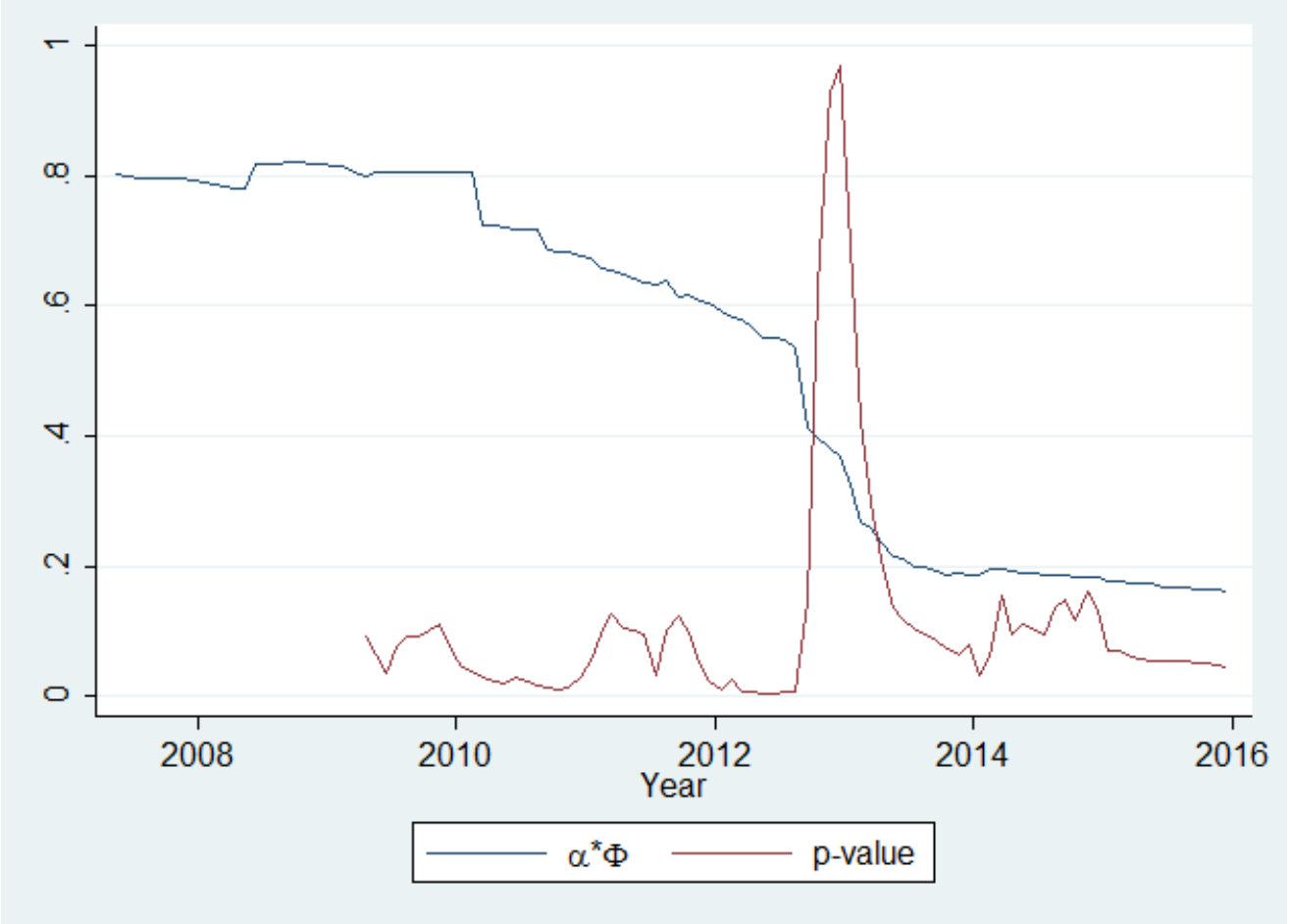

In the context of model (6), a lack of common trend between the two prices can be interpreted in the sense that the probability of CERs and EUAs being fungible assets becomes very small. Figure 9 shows this probabilty, given by $\hat{\alpha} \cdot \Phi\left(\varphi_{t} S_{0}^{t} /\left(\hat{\sigma} E\left[S_{0}^{T}\right]\right)\right)$, along with the p-value from the cointegration test. The probability measure drops from around 0.6 to below 0.2 after the switch of the time horizon from 2012 to 2020 in September 2012, which coincides with the loss in cointegration. These results suggest that market participants did not immediately incorporate the update in offset import rules in April 2009 (European Union, 2009), but continued to treat December 2012 as the relevant time horizon for offset imports for more than three years. 


\section{Discussion}

In this paper, we develop a theory of CER price formation. In our model, the spread between the EUA and the CER prices is driven by the possibility that CERs and EUAs may not end up being fungible assets, due to a binding limit for the use of offsets in the EU ETS and limited demand for offsets by Annex B countries. We thus motivate the price spread by import rules and demand and supply of offsets, even in the absence than transactions costs.

We provide empirical evidence for our theory. We model the probability that the import limit turns out to be nonbinding (and thus that EUAs and CERs are fungible assets) using data about offset supply from the UN's CDM/JI pipelines, which we correct for delayed project starts and varying rates of issuance success. This data is crucial to understand the availability of offsets, but has not been used to empirically investigate CER price formation to date.

In our base model, we find that the EUA price, weighted by the probability of nonbinding import rules, explains a large share of the CER price. When we relax some of our assumptions and use a more flexible functional form, we again find evidence for our theory in the sense that the CER price is a function of the interaction between the EUA price and the excess demand for offsets.

Our results further suggest that market participants did not immediately incorporate a decision issued by the EU in 2009, that EU ETS firms may transfer any unused offset import limits to Phase III, which were originally designed to be used in Phase II only. This implies that the relevant time horizon for evaluating the expected demand and supply of offsets from December 2012 to December 2020. However, based on our model, market participants continued to treat December 2012 as the relevant time horizon until August 2012, more than three years after the EU's rule update. This led to a too high CER price, and thus to an increase in the overall cost of achieving the Kyoto targets. Our analysis therefore highlights the importance of informational frictions in the context of large-scale polices, especially concerning the communication of rule updates. 


\section{References}

Braun, Nathan, Timothy Fitzgerald, and Jason Pearcy (2015) "Tradable Emissions Permits with Offsets," in Marc Gronwald and Beat Hintermann eds. Emissions Trading as a Policy Instrument: Evaluation and Prospects: MIT Press, p. 239.

Chevallier, Julien (2012) "EUAs and CERs: Interactions in a Markov regime-switching environment," Economics Bulletin, Vol. 32, No. 1, pp. 86-101.

Engle, Robert F. and Clive W.J. Granger (1987) “Co-Integration and Error Correction: Representation, Estimation, and Testing," Econometrica, Vol. 55, No. 2, pp. 251-276.

European Union, (2003) "Directive 2003/87/EC of the European Parliament and of the Council of 13 October 2003."

(2009) "Directive 2009/29/EC of the European Parliament and of the Council of 23 April 2009."

Grüll, Georg and Luca Taschini (2012) "Linking emission trading schemes: a short note," Economics of Energy \& Environmental Policy, Vol. 1, No. 3, pp. 31-38.

Hieroymi, Philipp and David Schüller (2015) “The Clean-Development Mechanism, stochastic permit prices and energy investments," Energy Economics, Vol. 47, pp. 25-36.

Kanamura, Takashi (2016) "Role of carbon swap trading and energy prices in price correlations and volatilities between carbon markets," Energy Economics, Vol. 54, pp. 204-212.

Koop, Gary and Lise Tole (2013) "Modeling the relationship between European carbon permits and certified emission reductions," Journal of Empirical Finance, Vol. 24, pp. 166-181.

Mansanet-Bataller, Maria, Julien Chevallier, Morgan Hervé-Mignucci, and Emilie Alberola (2011) "EUA and sCER phase II price drivers: Unveiling the reasons for the existence of the EUA-sCER spread," Energy Policy, Vol. 39, No. 3, pp. 1056-1069.

Nazifi, Fatemeh (2013) “Modelling the price spread between EUA and CER carbon prices," Energy Policy, Vol. 56, pp. 434-445. 
Phillips, Yangru Wu, Peter C.B. and Jun Yu (2011) "Explosive Behavior in the 1990s NASDAQ: When did Exuberance escalate Asset Values?" International Economic Review, Vol. 52, No. 1, pp. 201-226.

Rahman, Shaikh M. and Grant A. Kirkman (2015) "Costs of certified emission reductions under the Clean Development Mechanism of the Kyoto Protocol," Energy Economics, Vol. 47, pp. 129-141.

Trotignon, Raphael (2012) “Combining cap-and-trade with offsets: lessons from the EU-ETS," Climate Policy, Vol. 12, No. 3, pp. 273-287.

Trotignon, Rafael and Benoit Leguet (2009) “How Many CERs by 2013?”. Mission Climat Working Paper Nr. 2009-5.

UNFCCC, (2006) "Report of the Conference of the Parties serving as the meeting of the Parties to the Kyoto Protocol on its first session, held at Montreal from 28 November to 10 December 2005. Addendum, Part Two: Action taken by the Conference of the Parties serving as the meeting of the Parties to the Kyoto Protocol at its first session.” FCCC/KP/CMP/2005/8/Add.2.

(2013) "Afforestation and reforestation projects under the Clean Development Mechanism: A reference manual." http://www.unfccc.int.

(2015a) “CDM project cycle procedure.” CDM-EB65-A32-PROC, Version 9.0.

(2015b) "CDM project standard." CDM-EB65-A05-STAN, Version 9.0.

(2015c) “CDM validation and verification standard.” CDM-EB65-A04-STAN, Version 9.0. 


\section{Appendix}

Figure A1: Prices for CERs and ERUs

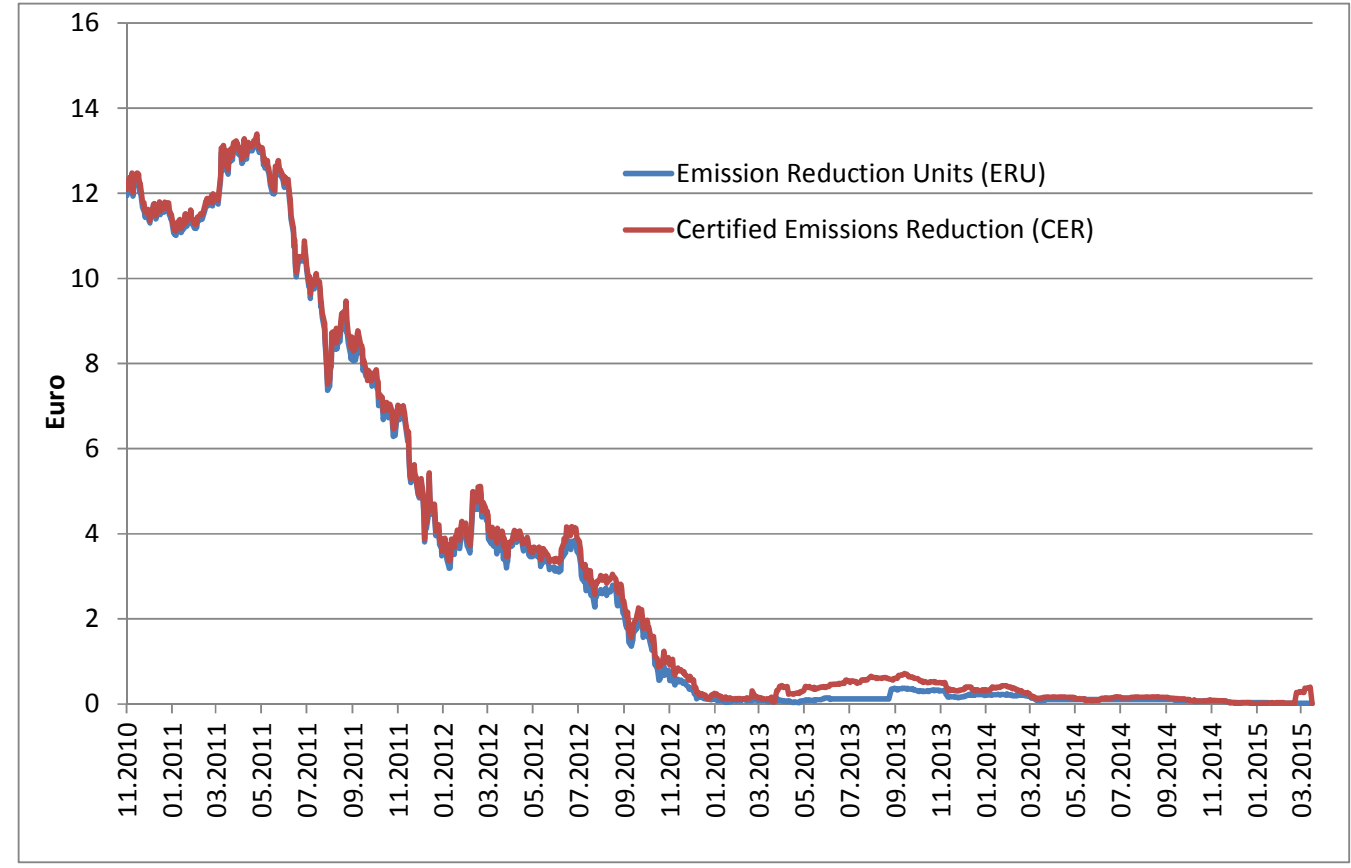

Source: 1-year futures from ICE, accessed via Thomson Reuters Eikon

Figure A2: Average delay between start of comment period and registration, by month of registration

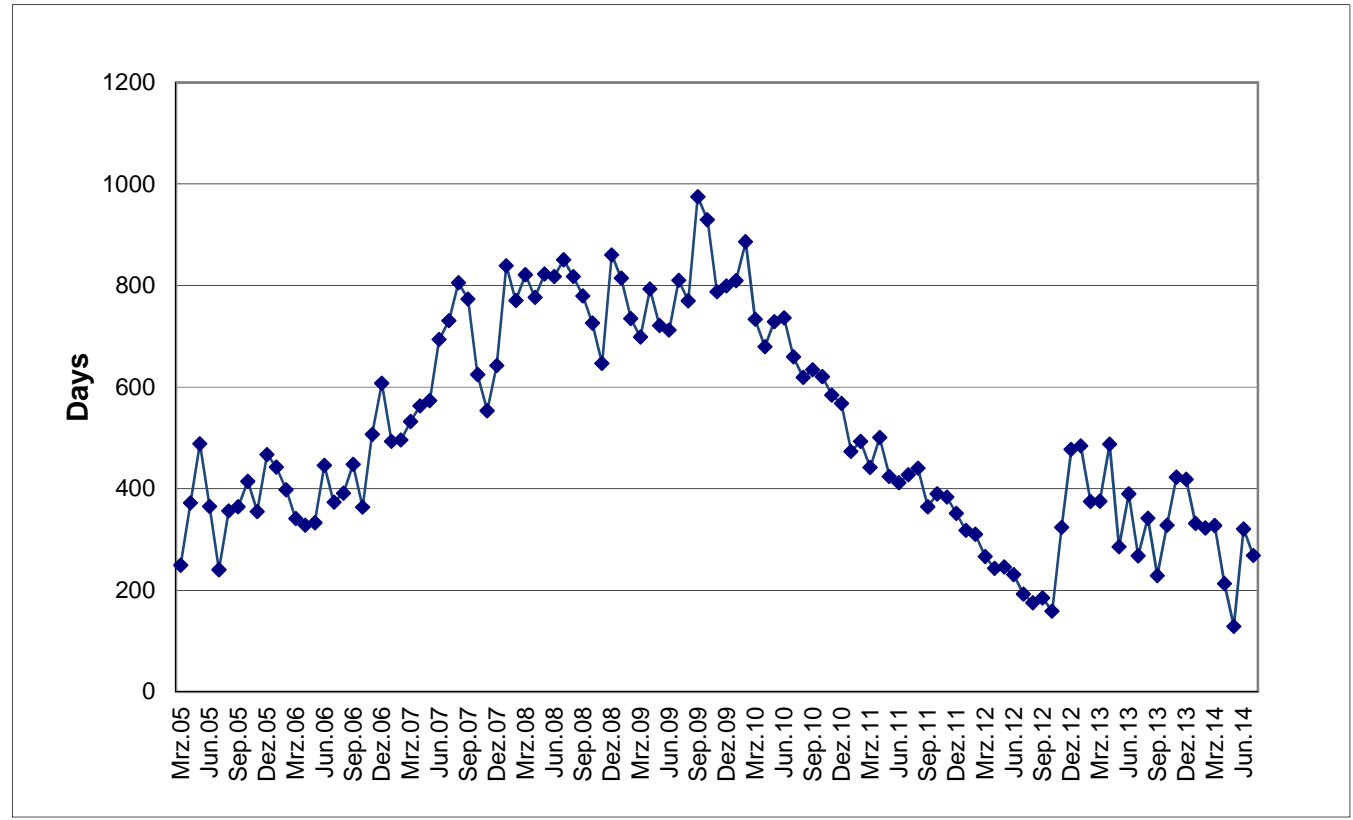

Source: CDM pipeline from December 2015, Graph 8 
Figure A3: Average delay between MR and issuance, by month of issuance

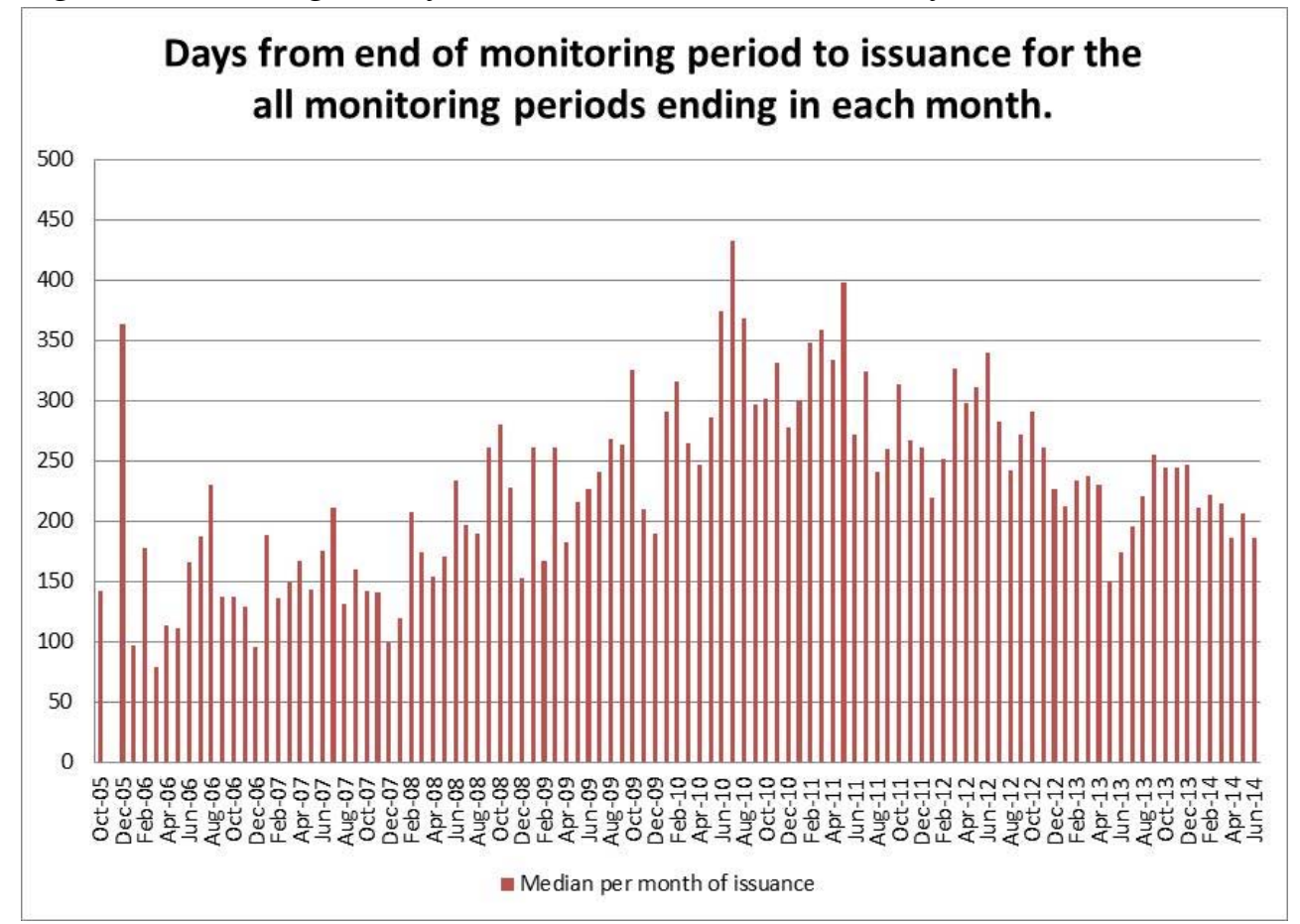

Source: CDM pipeline from December 2015, Graph 4

\section{Emissions reductions via the Joint Implementation (JI) mechanism}

The guidelines for participation in the JI mechanism are described in UNFCCC (2006). Parties may apply to one of two different JI "tracks". The first track consists in a simplified procedure that allows the host party itself to verify that emissions reductions of a project are indeed "additional to any that would otherwise occur" and issue the correspondent amounts of ERUs. Under track 2, verification and issuance of ERUs has to follow the verification procedure under the JI supervisory Committee (JISC). The track 2 procedure consists of five steps, which are summarized in Figure A4.

As in the CDM, the first step consists in project participants developing a project design document (PDD), which contains all the information specified in the JI guidelines. The PDD must show that the project has been approved by all the involved Parties, how the emission reductions are to be achieved, and that its baseline and monitoring plan is in line with the required criteria specified in JI guidelines. The PDD has to be submitted to an accredited independent entity (AIE), who makes the PDD publicly available for a 30-consultation period involving all relevant stakeholders. The AIE then determines whether the PDD provides all necessary information and makes its determination publicly available. If no review on the part of a Party involved in the project or the JISC is requested within 45 days, the PDD is "determined" to be final, which means that the project can be implemented. After 
implementation has started, project participants periodically have to submit a monitoring report about the achieved emissions reductions to an AIE (which is typically different to the AIE involved in the review of the PDD). The monitoring report is made publicly available, and the AIE has to verify the emission reductions. This verification report then is again made publicly available and declared final after 15 days, provided that no review on the part of a Party involved in the project or the JISC is requested. The last step consists in the issuance of Emissions Reduction Units (ERUs) according to the number of verified tons of $\mathrm{CO}_{2}$ during the monitoring period.

Figure A4: JI project cycle

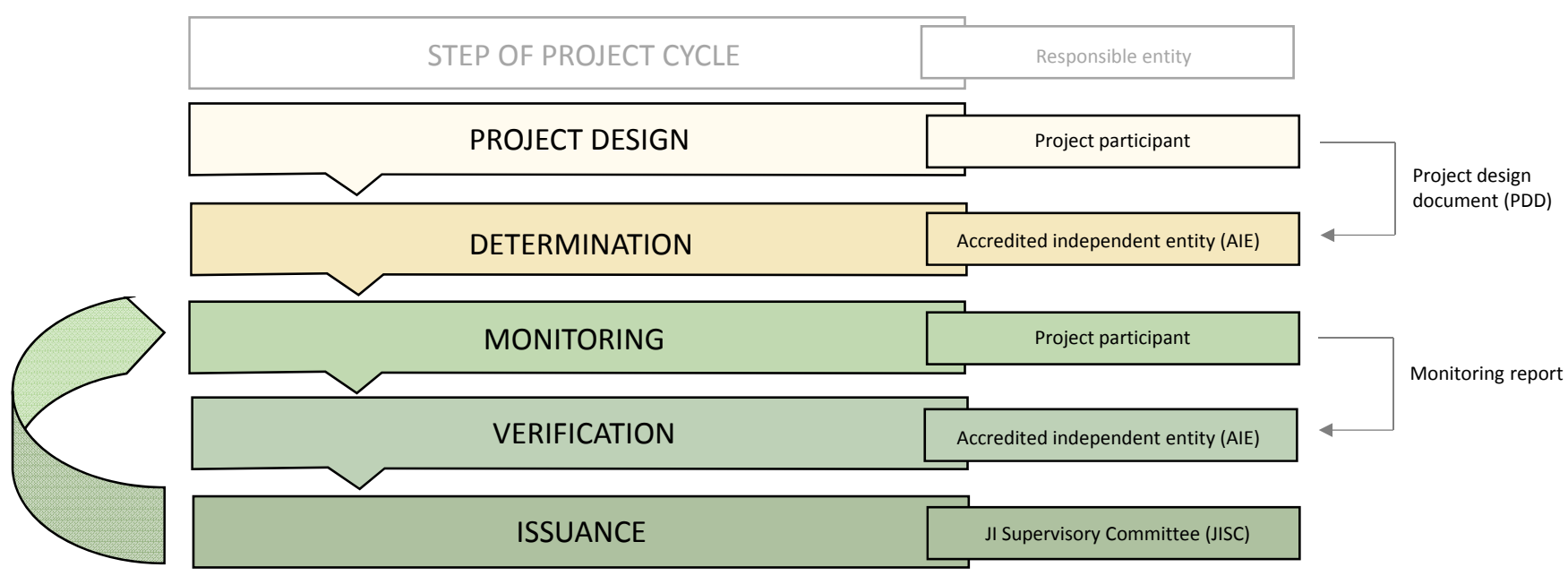

Source: Own illustration based on information in UNFCCC (2006) 